\title{
Fungi colonizing wood sticks of Chinese fir incubated in subtropical urban soil growing with Ficus microcarpa trees
}

\author{
S. Ding ${ }^{1} \cdot$ H. Hu ${ }^{1,2} \cdot$ J.-D. Gu${ }^{1}$
}

Received: 1 October 2013/Revised: 3 January 2014/Accepted: 15 March 2015/Published online: 9 April 2015

(C) Islamic Azad University (IAU) 2015

\begin{abstract}
Fungi colonized on wood sticks of the Chinese fir Cunninghamia lanceolata after incubation in soil around the Ficus microcarpa trees were isolated. In total, 1189 wood sticks from $28 \mathrm{~F}$. microcarpa trees were sampled and analyzed in this study. A combined approach of culture morphological observation and PCR amplification of ITS of purified fungal isolates in revealing restriction fragment length polymorphism patterns was applied to group the purified fungal isolates for further species identification. Fungal species were identified based on phylogenetic analysis of ITS and $\beta$-tubulin gene-amplified sequences. Overall, 25 species belonging to 17 genera from four classes were identified, and all of them were Ascomycota. Among them, Penicillium spp., Fusarium spp., and Phoma insulana were the most frequently isolated. In this study, Dichotomonyces cejpii, Fusicolla acetilerea, and Purpureocillium lilacinum are recorded in Hong Kong for the first time. Some species of the fungal cultures obtained in this study may have potential application as biocontrol agents to control tree disease.
\end{abstract}

S. Ding and H. Hu contributed eqaually to this work and therefore they should be treated as co-first authors.

Electronic supplementary material The online version of this article (doi:10.1007/s13762-015-0802-5) contains supplementary material, which is available to authorized users.

\section{J.-D. Gu}

jdgu@hku.hk

1 Faculty of Science, School of Biological Sciences, The University of Hong Kong, Pokfulam Road, Hong Kong SAR, People's Republic of China

2 Ministry of Agriculture Key Laboratory of Subtropical AgroBiological Disaster and Management, Fujian Agriculture and Forestry University, Fuzhou 350002, China
Keywords ITS · RFLP · Soil fungi · Taxonomy · Urban environment $\cdot$ Incubation

\section{Introduction}

Fungi play an important role in maintaining the carbon and nutrient cycling of the urban ecosystem, and they are also crucial in either maintaining the health or causing diseases of the trees (Burke et al. 2011). The natural community of fungi can form a barrier to resist the invasion of exotic fungi, which may threaten local fungal diversity and also the health of local trees (Berendsen et al. 2012). The balance of different fungal species in the form of higher diversity may prevent some opportunistic fungal species turning into pathogens. However, when the trees are senescent and/or weak, opportunistic pathogenic fungi may invade and cause disease and damages to the trees (Gazis and Chaverri 2010).

In urban environment, biodiversity of fungal community in trees grown soils is relatively low, which may be caused by the intense human impact, poor growing condition, environmental pollution, transplantation of seedlings, which may carry pathogens to trees, and low biodiversity of roadside trees (Newbound et al. 2010). The low diversity of the fungal community may result in a lack of antagonistic fungal species, therefore, allowing pathogens including opportunistic pathogens to cause infection of the trees and further damage of the physical property of the trees. Under such circumstance, the existence of antagonistic fungi is extremely important to the maintenance of tree health. Therefore, it is important to know the fungal communities in the urban soil and the fungal species that can cause significant damage of the trees. 
The conventional culture-dependent methods usually end up with a large number of isolates. Identification by checking the morphology of each culture strain can be tedious. An alternative can be molecular approaches, such as restriction fragment length polymorphism (RFLP), denaturing gradient gel electrophoresis (DGGE), and temperature gradient gel electrophoresis (TGGE), which are usually applied in ecological and biodiversity studies of fungi by culture-independent method (Viaud et al. 2000). These methods could be used to group fungal isolates according to DNA band patterns of electrophoresis. Species identification within each group of identical electrophoresis position can be achieved selectively with phylogenetic analysis of the obtained DNA sequences through comparison with relevant sequences from GenBank, and morphological characteristics could also be applied as confirmation of the individual species. Such combined approach of methods provides a faster and more accurate means to identify fungal species, despite the subtle culture morphological similarities of different species or significant culture morphological differences of the same species or the failure of sporulation in the culturing process on agar plates.

In this study, both culture-dependent and molecular methods were combined to investigate the composition of fungal community on wood sticks incubated in soils along the Nathan Road, Kowloon, Hong Kong; to interpret their possible function in the urban ecosystem; and to explore and test the application of molecular approaches in study of fungal community in urban environment. This study was conducted in urbanized Kowloon of Hong Kong in February 2011.

\section{Materials and methods}

\section{Sampling site information}

Nathan Road is a main road at Tsim Sha Tsui in Kowloon of Hong Kong, which connects several different commercial centers. It is one of the busiest roads with high volume flow of both vehicles and visitors. Both sides of the road are mostly planted with the Chinese banyan trees Ficus microcarpa. These trees have been grown there for several decades and are delightful signs of the cosmopolitan against the background skyscrapers and the crowd of locals and visitors (Supplement Fig. S1). However, some of the $F$. microcarpa are showing decline of health not only because of senescence, but also due to the restricted living environments and poor condition for growth. Walls made of bricks/stone and cement were built around the base of the trees with soil filling into the area. Various underground utilities also create barrier to the growth of the roots for extension. These conditions restrict the spreading and growth of the banyan roots for access of water and nutrients. In addition, growing urban pollution, improper trimming, and the invasion of plant pathogens also contribute to the health declination of the trees. In order to better understand the microflora that trees are exposed to and take more effective proactive mitigation plans to protect the trees and improve their health conditions, it is crucial to gather information on the fungal community in the soils grown with $F$. microcarpa.

\section{Study sites and sample collection}

The study was carried out on Nathan Road in Kowloon of Hong Kong in February, 2011. Wood sticks of the Chinese fir Cunninghamia lanceolata were used as baits for the soil fungi to colonize. The wood sticks $(1 \times 1 \times 70 \mathrm{~cm})$ were inserted into the soil about $60-65 \mathrm{~cm}$ in depth surrounding a $F$. microcarpa tree in 16 directions and four at each direction with $1 \mathrm{~m}$ of interval away from the tree according to the space availability (Fig. 1). Theoretically, there were 64 wood sticks for each tree, and the actual number was less than this due to the availability of space in all four directions for any of the 28 trees. They were incubated in the soil for at least 20 days, then retrieved, sealed in individual plastic bags, and brought back to the laboratory for further examination and isolation of fungi.

\section{Isolation and purification of fungal isolates}

Isolation of fungi was carried out in the sterile laminar-flow hood. Four segments $(2 \times 2 \mathrm{~mm})$ were cut from each of

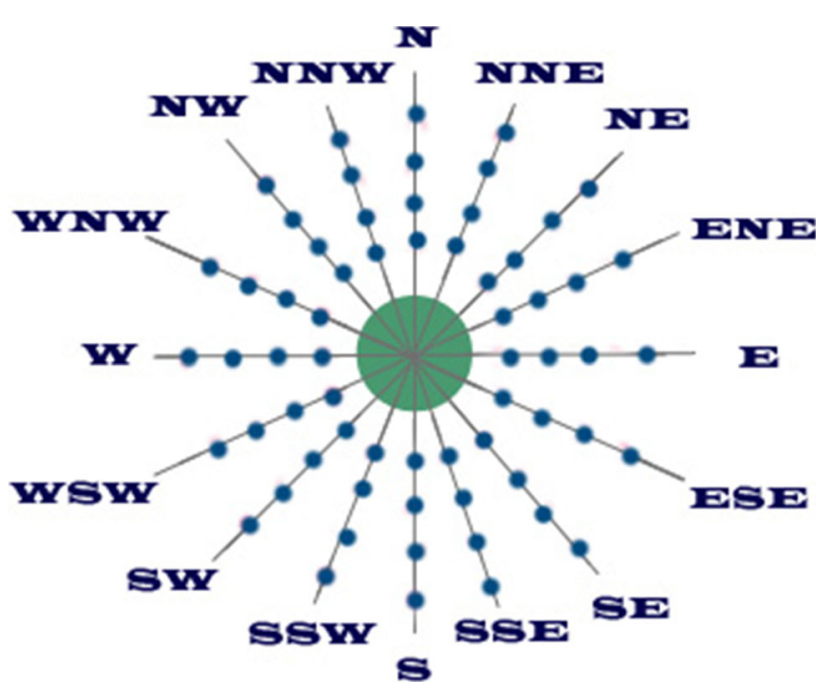

Fig. 1 Schematic diagram of maximum wood sticks deployments surrounding each $F$. microcarpa tree. Due to space availability, the actual number varied 
the wood sticks, soaked in $75 \%$ ethanol for $1.5 \mathrm{~min}$, and then rinsed three times in sterile water before placed on malt extract agar (MEA) (BD Difco ${ }^{\mathrm{TM}}$ ) plate, which consists of $20 \mathrm{~g} / \mathrm{l}$ malt extract, $20 \mathrm{~g} / \mathrm{l}$ agar, $10 \mathrm{mg} / \mathrm{l}$ benomyl, $10 \mathrm{mg} / \mathrm{l}$ dicloran, $100 \mathrm{mg} / \mathrm{l}$ ampicillin, and $500 \mathrm{mg} / \mathrm{l}$ gallic acid (Chang 1995). Then the plates were incubated at room temperature $\left(25^{\circ} \mathrm{C}\right)$ for 4 weeks. Colonies developed on the plates were further transferred to potato dextrose agar (PDA) (BD Difco ${ }^{\mathrm{TM}}$ ) plates, containing $0.05 \%$ streptomycin, and incubated at room temperature for purification. Subculture on PDA plates was repeated until the structure and color of the culture on agar plate were identical to those on the initial plates.

\section{PCR-RFLP}

Total genomic DNA of each purified isolates was extracted directly by grinding approximately $0.5 \mathrm{~g}$ mycelia (wet wt) in a mortar with liquid nitrogen and then transferring to a sterile 1.5-ml Eppendorf tube. CTAB method was used for DNA extraction (Lacap et al. 2003). The specific steps were as the followings. First, $600 \mu \mathrm{l}$ of $2 \times \mathrm{CTAB}$ was added into the tube and then incubated at $65{ }^{\circ} \mathrm{C}$ for $1 \mathrm{~h}$, during which vortex was made every $10 \mathrm{~min}$. Then $600 \mu \mathrm{l}$ of phenol/chloroform $(1: 1, \mathrm{v} / \mathrm{v})$ was added, mixed, and then centrifuged at $14,000 \mathrm{rpm}$ for $25 \mathrm{~min}$, and the upper aqueous layer was transferred into a new Eppendorf tube. This step was repeated twice. Then $900 \mu$ l of absolute ethanol was added, and the tube was kept at $-20{ }^{\circ} \mathrm{C}$ over night and centrifuged at $11,000 \mathrm{rpm}$ at $4{ }^{\circ} \mathrm{C}$ for $45 \mathrm{~min}$. The supernatant was discarded, and the DNA pellet was washed with $70 \%$ ethanol twice. After drying up in the sterile hood, the DNA pellet was dissolved in $100 \mu \mathrm{l}$ of $10 \times \mathrm{TE}$ without RNase and stored at $4{ }^{\circ} \mathrm{C}$ for further experiments.

PCR was carried out with universal primers ITS1F (5'CTT GGT CAT TTA GAG GAA GTA A-3') (Gardes and Bruns 1993) and ITS4 (5'-TCC TCC GCT TAT TGA TAT GC-3') (White et al. 1990). Maxime PreMix (Intron Biotechnology) was used during the PCR amplification with $1 \mu \mathrm{l}$ of ITS1F $(20 \mu \mathrm{M}), 1 \mu \mathrm{l}$ of ITS4 $(20 \mu \mathrm{M}), 2 \mu \mathrm{l}$ of template DNA (approximately $10 \mathrm{ng}$ ), and $16 \mu \mathrm{l}$ of sterilized water (total volume of $20 \mu \mathrm{l}$ ). The protocol of thermal cycling parameters (Cai et al. 2005, 2006) with modification included an initial denaturation at $95{ }^{\circ} \mathrm{C}$ for $3 \mathrm{~min}$, followed by 30 cycles consisting of denaturation at $95{ }^{\circ} \mathrm{C}$ for $1 \mathrm{~min}$, annealing at $52^{\circ} \mathrm{C}$ for $1 \mathrm{~min}$, and extension at $72{ }^{\circ} \mathrm{C}$ for $1 \mathrm{~min}$. A final extension at $72{ }^{\circ} \mathrm{C}$ for $10 \mathrm{~min}$ was added at the end of the thermal cycling. PCR products were visualized on $1 \%$ agarose electrophoresis gels stained with GelRed $^{\mathrm{TM}}$ nucleic acid gel stain (Biotium) to check for product purity and size. PCR products were purified by using GFX ${ }^{\mathrm{TM}}$ PCR RNA and Gel Band Purification Kit
(Amersham Biosciences) under the guide of the manufacturer's protocol.

The purified PCR products of ITS rDNA were treated in two ways. On the one hand, some of the purified PCR products were digested with two restriction enzymes HaeIII and HinfI (Takara) following the manufacturer's instruction. Each reaction contained $5 \mu \mathrm{l}$ of purified PCR product (about $5-10 \mathrm{ng}$ ), $1 \mu \mathrm{l}$ of buffer, $0.5 \mu \mathrm{l}$ of restriction enzyme $(50 \mu \mathrm{M})$, and $3.5 \mu \mathrm{l}$ of sterile water (total volume of $10 \mu \mathrm{l})$. Then the mixture was incubated at $37^{\circ} \mathrm{C}$ for $2 \mathrm{~h}$. The RFLP results were checked on $2 \%$ agarose electrophoresis gels stained with GelRed. The pattern of the RFLP results was recorded and grouped. On the other hand, in each identified different group, one or several purified PCR products were sequenced at Genome Research Centre, The University of Hong Kong).

For certain groups of fungi which could not be identified to species level or did not achieve high branch support with ITS rDNA, $\beta$-tubulin gene was amplified with the primer pair T1 (5'-AAC ATG CGT GAG ATT GTA AGT-3') and T2 (5'-TAG TGA CCC TTG GCC CAG TTG-3') (O'Donnell and Cigelnik 1997). The PCR amplification using Maxime PreMix in a total volume of $20 \mu \mathrm{l}$ was carried out with $1 \mu \mathrm{l}$ of $\mathrm{T} 1(20 \mu \mathrm{M}), 1 \mu \mathrm{l}$ of $\mathrm{T} 2(20 \mu \mathrm{M})$, $2 \mu \mathrm{l}$ of template DNA (approximately 10-15 $\mathrm{ng}$ ), and $16 \mu \mathrm{l}$ of sterilized water. The protocol of thermal cycling parameters following that for ITS rDNA with modification included an initial denaturation at $95{ }^{\circ} \mathrm{C}$ for $3 \mathrm{~min}$, followed by 30 cycles consisting of denaturation at $95^{\circ} \mathrm{C}$ for $1 \mathrm{~min}$, annealing at $54{ }^{\circ} \mathrm{C}$ for $1 \mathrm{~min}$, and extension at $72{ }^{\circ} \mathrm{C}$ for $1 \mathrm{~min}$. A final extension at $72{ }^{\circ} \mathrm{C}$ for $10 \mathrm{~min}$ was added at the end of the thermal cycling. The subsequent steps were the same as that for ITS rDNA.

\section{Phylogenetic analysis}

The obtained sequences were checked with BioEdit (Hall 1999), mainly for the sequence accuracy, deleting varied characters at the beginning and the end and modifying the varied characters in the sequences. Each sequence was BLASTed in NCBI (http://www.ncbi.nlm.nih.gov/) to confirm the sequence validity. Together with other closely related sequences (Supplement Table S1 and S2), the sequences were aligned using CLUSTALX (1.83) (Thompson et al. 1997). Manual adjustments were made in BioEdit by inserting gaps to improve the alignments. Then the alignments were converted to NEXUS files using CLUSTALX for phylogenetic analysis in PAUP (Phylogenetic Analysis Using Parsimony) v.4.0b10 (Swofford 2002). Any ambiguously aligned regions were excluded from phylogenetic analyses.

Data sets were initially analyzed using maximum parsimony (MP). The heuristic search option was used, 
ignoring constant and uninformative characters. Random addition of sequences for 5000 replicates with tree bisection-reconnection (TBR) branch swapping was performed. MulTrees option was in effect, and zero-length branches were collapsed. Gaps were treated as missing data. Tree scores, including tree length (TL), consistency index (CI), retention index (RI), rescaled consistency index (RC), and homoplasy index (HI), were also calculated for all the trees generated under different parameters. Branch support and stability for all MP analyses were assessed by bootstrap analysis (Felsenstein 1985). Bootstrap analysis was carried out based on 1,000 resampled data sets analyzed with random addition of taxa.

MrModeltest 2.2 (Nylander 2004) was used to get the best-fit model of substitution for maximum likelihood (ML) analyses and MrBayes analyses. ML analyses were carried out using heuristic search, with addition sequence set to "asis" and TBR branch swapping algorithm. Bayesian posterior probability was calculated by using MrBayes v3.0 (Huelsenbeck and Ronquist 2001). The implemented model was the same as that for ML analysis. One million generations were run for six chains and sampled every 100th generations resulting in 10,000 trees. The first 2,000 trees were discarded because they represented the burn-in phase of the analyses, and the remaining 8,000 trees were used to calculate the posterior probabilities in a consensus tree. Trees were viewed in Treeview (Page 1996).

The PCR-amplified sequences of ITS and $\beta$-tubulin genes of this study are assigned with accession numbers KF596337-KF596438 and KF596439-KF596512.

\section{Results and discussion}

\section{Fungal colonization on wood sticks}

In total, 1189 wood sticks were deployed and incubated around 28 F. microcarpa trees along the Nathan Road. All the 1189 of them were retrieved successfully after at least 20 days of incubation, but 166 of them were analyzed in this study due to the low diversity of fungal isolates obtained through increasing the number of samples analyzed. Because of this, no further examination of the remaining samples was carried out. These wood sticks were all visually intact without indication of apparent decomposition. However, all the sticks showed discoloration to some extent, either in forms of spots or patches (Supplement Fig. S2). Staining colors ranged from gray-blue to black. Wood sticks retrieved from the tree OVT35 appeared to be more intense coloration than the others.

Conventional isolation and culturing technique were used to isolate and culture the fungi from the wood sticks. After isolation and purification, 324 fungal isolates were obtained from 166 wood sticks, about $14 \%$ of all the wood sticks incubated initially. Of the 166 wood sticks, approximately two isolates were obtained from each stick on average. Wood sticks retrieved from trees OVT35 and OVT36 showed significantly more isolates, about 3.45 and 4.25 isolates per stick on average, respectively. This uneven distribution of fungal colonization may be related to the urban environment (Newbound et al. 2010). Though all of the trees are grown along one road in a city center, the fungal communities obtained from the soil of each tree were not uniform (Fig. 2). Such unevenness is largely caused by the highly variable underground conditions due to soil type and the construction of utilities and telecommunication. Wood sticks retrieved from OVT35, the tree with pipes constructed underneath, were heavily colonized, and as a result, more fungal isolates with higher species richness were obtained. Similar results were also evident from OVT34 and OVT36, which were on each side of OVT35, forming a straight line with only a few meters apart. Other factors, such as the health condition of the individual tree, are the most important one contributing to the different fungal community around each tree. Several trees such as OVT1, 2, 7, 8, 11, and 12 are seriously
Fig. 2 Number of fungal isolates and species richness obtained from each tree

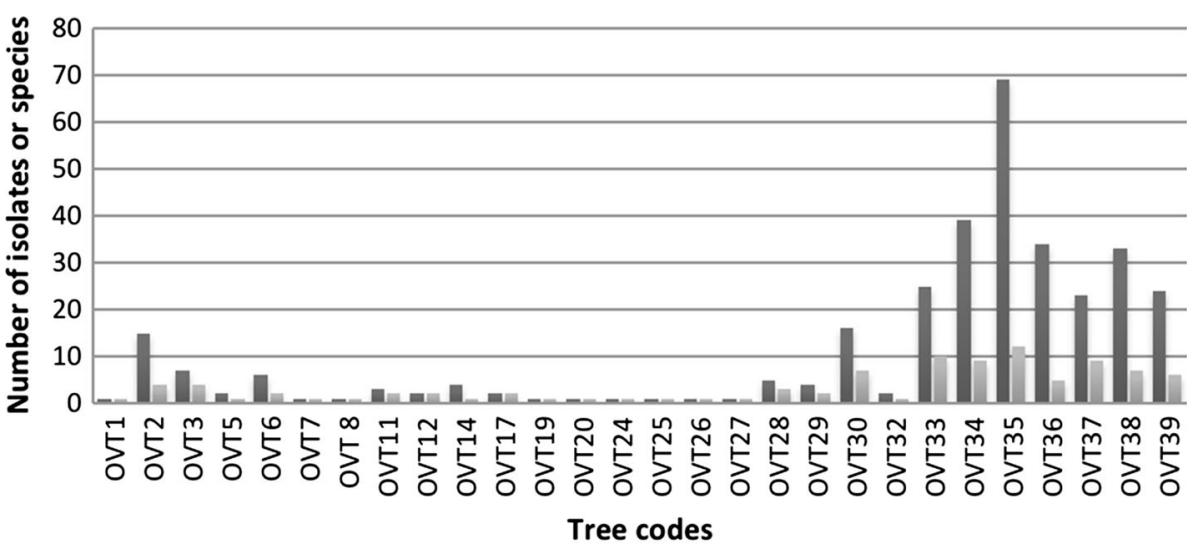

Qty of isolates Species richness 
Table 1 A list of identified fungal species and their abundances on the wood sticks in this study

\begin{tabular}{|c|c|c|c|c|}
\hline Species & $\begin{array}{l}\text { Isolates } \\
\text { number }\end{array}$ & $\begin{array}{l}\text { Percentage } \\
\text { of each } \\
\text { species } \\
(\%)\end{array}$ & $\begin{array}{l}\text { Occurrence } \\
\text { (number of } \\
\text { trees) }\end{array}$ & $\begin{array}{l}\text { Occurrence } \\
\text { rate }(\%)\end{array}$ \\
\hline $\begin{array}{l}\text { Amorphotheca } \\
\text { resinae }\end{array}$ & 15 & 4.63 & 3 & 13.04 \\
\hline Aspergillus niger & 1 & 0.31 & 1 & 4.35 \\
\hline $\begin{array}{l}\text { Bionectria } \\
\text { ochroleuca }\end{array}$ & 27 & 8.33 & 12 & 52.17 \\
\hline $\begin{array}{l}\text { Candida } \\
\text { parapsilosis }\end{array}$ & 2 & 0.62 & 1 & 4.35 \\
\hline $\begin{array}{r}\text { Cochliobolus } \\
\text { geniculatus }\end{array}$ & 1 & 0.31 & 1 & 4.35 \\
\hline $\begin{array}{l}\text { Cylindrocladiella } \\
\text { lageniformis }\end{array}$ & 3 & 0.93 & 3 & 13.04 \\
\hline $\begin{array}{l}\text { Dichotomomyces } \\
\text { ceijpii }\end{array}$ & 6 & 1.85 & 5 & 21.74 \\
\hline $\begin{array}{l}\text { Fusicolla } \\
\text { acetilerea }\end{array}$ & 1 & 0.31 & 1 & 4.35 \\
\hline $\begin{array}{l}\text { Fusarium } \\
\text { oxysporum }\end{array}$ & 32 & 9.88 & 9 & 39.13 \\
\hline $\begin{array}{l}\text { Fusarium } \\
\text { proliferatum }\end{array}$ & 3 & 0.93 & 1 & 4.35 \\
\hline Fusarium solani & 28 & 8.64 & 9 & 39.13 \\
\hline $\begin{array}{l}\text { Fusarium } \\
\text { verticillioides }\end{array}$ & 2 & 0.62 & 1 & 4.35 \\
\hline $\begin{array}{l}\text { Paecilomyces } \\
\text { formosus }\end{array}$ & 4 & 1.23 & 2 & 8.70 \\
\hline $\begin{array}{l}\text { Penicillium } \text { cf. } \\
\text { verruculosum }\end{array}$ & 1 & 0.31 & 1 & 4.35 \\
\hline $\begin{array}{l}\text { Penicillium } \\
\text { citrinum }\end{array}$ & 1 & 0.31 & 1 & 4.35 \\
\hline $\begin{array}{l}\text { Penicillium } \\
\text { pinophilum }\end{array}$ & 1 & 0.31 & 1 & 4.35 \\
\hline $\begin{array}{l}\text { Penicillium } \\
\text { purpurogenum }\end{array}$ & 3 & 0.93 & 3 & 13.04 \\
\hline Penicillium sp. 1 & 96 & 29.63 & 11 & 47.83 \\
\hline $\begin{array}{r}\text { Pestalotiopsis } \\
\text { disseminata }\end{array}$ & 4 & 1.23 & 2 & 8.70 \\
\hline Phoma insulana & 65 & 20.06 & 16 & 69.57 \\
\hline $\begin{array}{l}\text { Purpureocillium } \\
\text { lilacinum }\end{array}$ & 4 & 1.23 & 3 & 13.04 \\
\hline Pyrenochaeta sp. & 3 & 0.93 & 2 & 8.70 \\
\hline $\begin{array}{c}\text { Talaromyces } \\
\text { assiutensis }\end{array}$ & 3 & 0.93 & 2 & 8.70 \\
\hline $\begin{array}{c}\text { Trichoderma } \\
\text { atroviride }\end{array}$ & 8 & 2.47 & 5 & 21.74 \\
\hline $\begin{array}{l}\text { Trichoderma } \\
\text { hamatum }\end{array}$ & 10 & 3.09 & 4 & 17.39 \\
\hline
\end{tabular}

infected by different kinds of wood-decay fungi with obvious cavities developed on the tree trunk and fungal fruiting bodies growing on the tree. The fungal communities detected associated with these trees were relatively smaller. Urban soil conditions can reduce the biodiversity and alter the community structures of soil fungi through the limited nutrients and living space available for trees and the presence of heavy metals and other pollutants from anthropogenic sources (Perez-de-Mora et al. 2006). The highly populated urban environment of Hong Kong has many factors limiting the growth of the trees, such as reduced space restricting the spreading of tree roots, lower plant species diversity, pollution of both atmosphere and soil by vehicles, which are very likely to reduce the biodiversity of soil fungal community and, in turn, to pose threats to the survival of trees in the cosmopolitan city.

\section{Composition of community and diversity}

A total of 24 types of RFLP pattern with HaeIII and HinfI were observed for the 324 fungal isolates obtained from the 166 wood sticks. By combining culture and microscopic morphological characteristics, 25 species were established from the 324 isolates and 33 unique sequences of ITS rDNA were included in the ML tree constructed. Based on MrModeltest 2.2, model GTR $+\mathrm{G}$ was chosen for ML analyses and MrBayes analyses. Phylogenetic analysis indicated 25 taxa, which were further confirmed by microscopic observation as 25 fungal species (Table 1). According to ML tree generated based on ITS (Fig. 3), species of a family were well clustered. Branches were highly supported by bootstrap values and Bayesian PP values. ITS yielded high resolution to most of the taxa, but relatively lower resolution to the genus of Penicillium, Phoma, and Fusarium. $\beta$-tubulin, which contains more variable characters than ITS rDNA, was applied in these groups, but improvement was only evident in the resolution of the genus Fusarium (Fig. 4) (Myllys et al. 2001).

The 25 species (Table 1) identified in this study belonged to 17 genera from four classes, Eurotiomycetes, Sordariomycetes, Dothideomycetes, and Saccharomycetes, which were all Ascomycota (Ainsworth and Kirk 2008). Among them, the genera Penicillium, Fusarium, and Phoma were $31.5,20.1$, and $20.1 \%$ of all isolates, respectively. Phoma insulana was the most widely distributed with an occurrence rate of $69.6 \%$ of the trees sampled, followed by Penicillium spp. (69.5\%), Fusarium spp. (56.5\%), and Bionectria sp. (52.2\%). Despite the overlapping of distribution range of certain fungal species, no specificity was detected for the wood sticks or individual trees, which is in agreement with the previous studies in that saprotrophic fungi usually have low host specificity (Lodge 1997; Zhou and Hyde 2001). Isolate number and species richness obtained from each tree varied, ranging from 1 to 69 and 1 to 12, respectively (Fig. 2). 


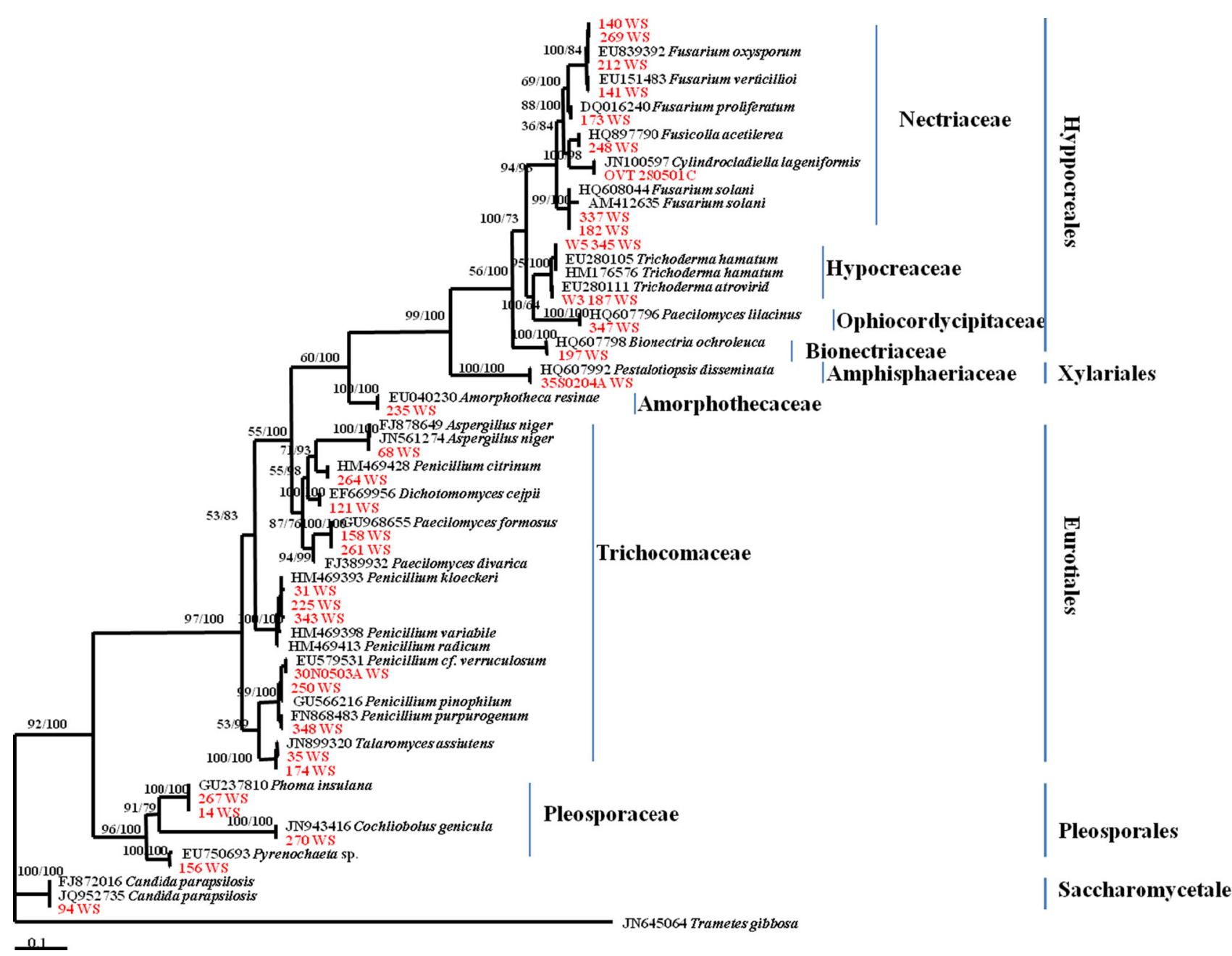

Fig. 3 Phylogenetic relationships among the 25 species obtained in this study. The tree was produced using maximum likelihood (ML) based on ITS region (ITS1, 5.8S, and ITS2). The numbers before

Generally, with the increasing number of fungi isolated from the incubated wood sticks, the diversity also showed an increase. Sixteen of these trees had less than five isolates obtained, but four (OVT34, 35, 36, 38) had more than 30 isolates. Seventeen of them had less than three fungal species detected, but one had 12 (OVT35).

Among the identified 25 species, Penicillium spp., Fusarium spp., and $P$. insulana were dominant in the fungal community (Table 1), which is ubiquitous not only in Hong Kong but also elsewhere ( $\mathrm{Lu}$ 2000; Yanna et al. 2002). A small number of Aspergillus niger, Cochliobolus geniculatus, Candida parapsilosis, Fusicolla acetilerea, and other species were also detected in this study, among which Cylindrocladiella lageniformis, Dichotomomyces ceijpii, $F$. acetilerea, $F$. proliferatum, $F$. verticillioides, Paecilomyces formosus, P. pinophilum, Purpureocillium lilacinum, and Talaromyces assiutensis have never been recorded or detected in Hong Kong before. One important slashes indicate bootstrap values; the numbers after slashes indicate Bayesian PP values. Sequences in red were obtained from this study

reason might be that there are very few relevant studies conducted in Hong Kong.

According to previous reports, most of the fungi detected in this study are very active in plant cell wall degradation (Fukasawa et al. 2011). Fusarium solani and Trichoderma spp. can cause significant weight loss of wood (Fukasawa et al. 2011). Penicillium spp. and Amorphotheca spp. isolated from dead beech (Fagus crenata) trees were also discovered to have cellulolytic activities (Fujii et al. 2010), which enabled them to degrade wood. Paecilomyces formosus, detected in tropical and subtropical soils and wood, suggests that these fungi are capable of degrading plant debris (Grafenhan et al. 2011; Samson et al. 2009). Pestalotiopsis spp. can be found in soil, and they can decompose plant debris (Osono and Takeda 1999; Xu et al. 2010). In this study, by the time when the fungal community was examined after the relatively short period of incubation, most of the decays on 


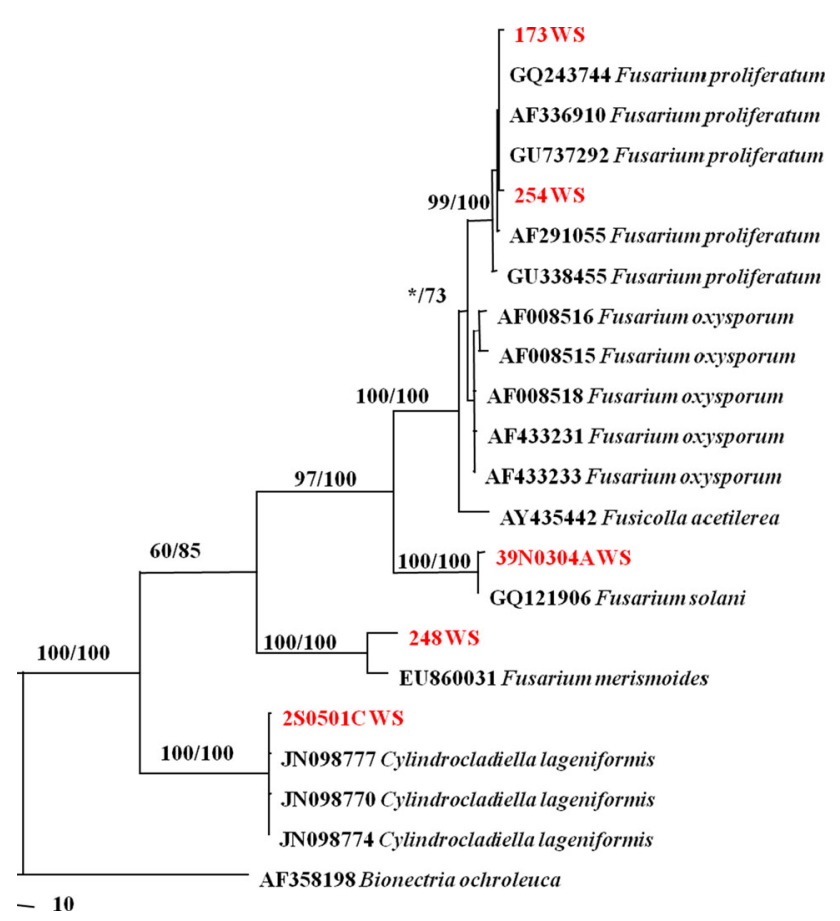

Fig. 4 Phylogenetic relationships among species from the family of Nectriaceae. The tree was produced using MP based on $\beta$-tubulin. The numbers before slashes indicate bootstrap values; the numbers after slashes indicate Bayesian PP values; asterisk indicates a supporting rate less than $50 \%$. Sequences in red were obtained from this study

the wood sticks developed were quite superficial, which might be categorized as soft rot. Soft rot, mostly caused by Ascomycetes mainly degrading cellulose and hemicelluloses on the surface layer of the wood, is not as severe as the other two types of rot, white-rot decay and brown-rot decay, which degrade either lignin or cellulose and hemicellulose rapidly and extensively (Bucher et al. 2004). Despite moderate decay by the soft-rot fungi, they are still crucial in the urban ecosystem as a decomposer of plant litter in the soil.

Incubation of wood-stick method could provide a glimpse of the soil fungi, which not only colonize on wood sticks, but also are the main decomposers of wood debris in the soil (Deacon et al. 2006; Kodsueb et al. 2008). Even though a small number of saprotrophic fungi were obtained, a large number of fungi were not isolated through the culturing and incubation methods used inevitably due to the limitations of the medium composition and selectivity as well as the slow-growing characteristics of some fungi. In this study, only $14 \%$ of the wood sticks resulted in successful fungal isolation and more than half of the trees had only less than five isolates. However, the result is not unexpected. Firstly, an exclusion of some fungal species was inevitable given that the strong and large doses of antibiotics applied in the culture media used. Secondly, saprotrophic fungi which can colonize and live on wood sticks are only part of the entire soil fungal community, and among these fungi, only a small portion could grow on artificial culture media in the incubation condition provided. Besides, some fungi may require a longer incubation time to establish colonies on the wood sticks, such as basidiomycetes, which are also important decomposers of wood in natural community and have been reported to account for a significant portion of fungal biomass in the soil (Gams 2007), but none of them was detected in this study. Therefore, in order to thoroughly study and present a more complete community of the wood decomposing fungi in the soil, different length of incubation time and more broad culture media or culture-independent method would be necessary.

\section{Evaluation of molecular detection of taxon and species}

Two commonly used restriction enzymes HaeIII and HinfI were applied to ITS rDNA in detecting species (Viaud et al. 2000; Aanen et al. 2001; Granchi et al. 1999). Different species showed clearly different RFLP patterns for three species in the genus of Fusarium and species from different genera (Fig. 5). At the same time, most closely related species according to taxonomic classification (Ainsworth and Kirk 2008) showed similar patterns, such as Pyrenochaeta sp. and $P$. insulana showed similar pattern with HinfI, and Pyrenochaeta sp. and C. geniculatus (lane 11) showed similar patterns with HaeIII. All of the above three species belonged to the same order. However, there was also an exception, Trichoderma atroviride and Trichoderma hamatum showed the same RFLP patterns as in Lanes 1-3 for T. atroviride, and lanes 4-10 for T. hamatum (Fig. 6).

According to the patterns of RFLP, restriction enzymes HaeIII and HinfI of ITS rDNA could successfully distinguish fungi from different genera and most species from the same genus. However, for some fungal species of the same genus, because of their extremely similar sequences of ITS rDNA, identical RFLP patterns may end up with different species of the same genus, such as $T$. atroviride and T. hamatum. In addition, in some cases, different species show the same restriction patterns (Fig. 5, upper, lanes 1 and 2, lanes 10 and 12) or contain no specific recognition site of certain restriction enzyme (Fig. 5, lanes 1,2 , and 12). Therefore, application of more restriction enzymes and better selection of enzymes would lead to better distinction of different species. Results of RFLP in this study agreed with those of Viaud et al. (2000), indicating that identical RFLP patterns show very closely related DNA sequences (Viaud, et al. 2000). It is clear that RFLP is an effective method in detecting the differences of 

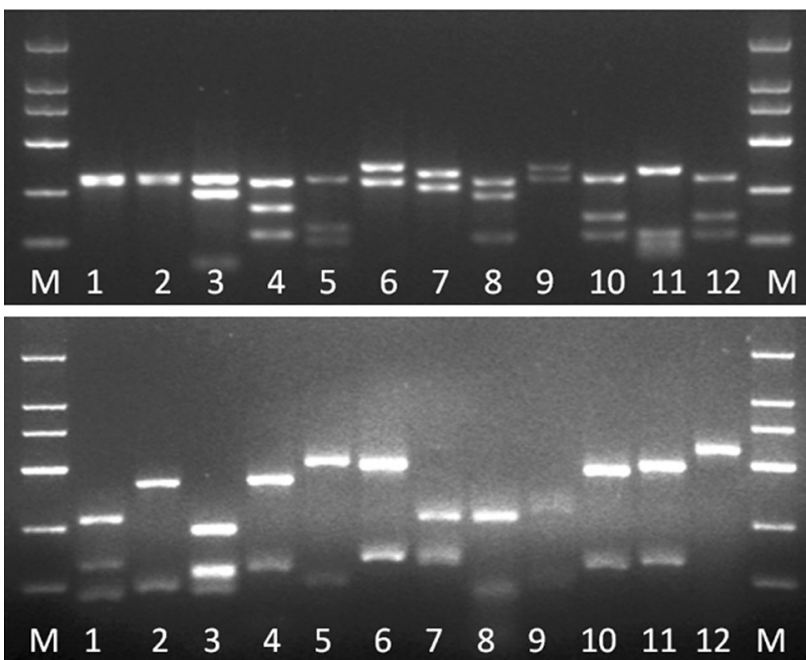

Fig. 5 Restriction patterns of different species. The upper figure shows RFLP patterns with restriction enzyme Hinfl; the lower figure shows RFLP patters with restriction enzyme HaeIII. 1 F. proliferatum, $2 \mathrm{~F}$. acetilerea, $3 \mathrm{~F}$. solani, 4 Bionectria ochroleuca, $5 \mathrm{C}$. lageniformis, 6 Pestalotiopsis disseminata, 7 Amorphotheca resinae, 8 D. ceijpii, 9 P. formosus, 10 Pyrenochaeta sp., 11 C. geniculatus, and 12 P. insulana
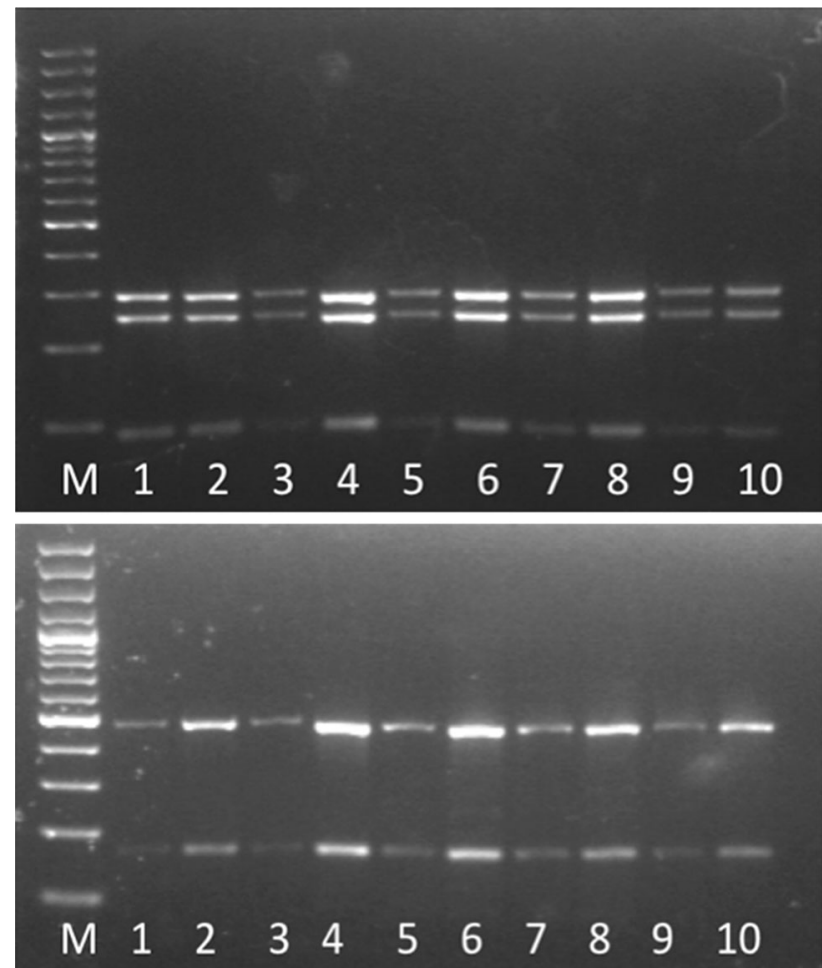

Fig. 6 Restriction patterns of $T$. atroviride (lanes 1-3) and $T$. hamatum (lanes 4-10). The upper figure shows RFLP patterns with restriction enzyme Hinfl; the lower figure shows RFLP patterns with restriction enzyme HaeIII
PCR-amplified sequences, whereas identification of the fungal species can be improved when combining with morphological characteristics.

ITS rDNA is widely used in the identification of fungal species because it contains both variable and conserved regions. However, for some genera, such as Penicillium and Phoma, which contain large numbers of species, ITS cannot yield high resolution in phylogenetic analysis (Aveskamp et al. 2010; Samson et al. 2011). In this study, $\beta$-tubulin, which contains more variable regions, was used for more specific species identification of Penicillium, Phoma, and Fusarium. However, the combination of the two genes could not accurately identify some species in Penicillium and Phoma on molecular scales, and this may be because of the availability of the relevant gene sequences in the GenBank or these groups are better identified with other specific genes (Schoch et al. 2012). Despite this, such multiple gene combination obviously allows a better resolution of the species identification (Rokas and Carroll 2005).

Theoretically, culture-dependent method would inevitably lead to the omission of the unculturable fungi and some slow-growing ones. In particular, culture-dependent method has its own advantages. In this study, the culture morphology provided an important reference to the identification of the fungal species. At the same time, more than 300 of fungal isolations were obtained, among which some could be potentially used as biocontrol agents. Trichoderma species were reported to antagonize against wood-decaying fungi such as Phellinus noxius and Ganoderma spp. (Schwarze et al. 2012), and P. lilacinum has long been studied as biocontrol agent to control the growth of destructive root-knot nematodes (Deng et al. 2012; LuangsaArd et al. 2011).

\section{Conclusion}

In this study, wood sticks allowed isolation and identification of fungi from urban soil. RFLP has successfully detected fungal species from different genera except two species from Trichoderma, so combined with culture morphology and microscopic observation, different fungal species can be distinguished. Identification with ITS rDNA and/or ß-tubulin is faster and more accurate than traditional identification methods only based on colony and microscopic characteristics. Most of the fungal species detected with the wood sticks in this study can decompose wood materials and therefore may play an important role in nutrient cycling in the urban ecosystem. Fungal cultures isolated from this study may possess special functions such as antagonistic toward plant pathogens, which could be further investigated. 
Acknowledgments This study was supported by project No. DEVB(SS) Q058/2010 from the Tree Management Office, Development Bureau of the Hong Kong SAR Government. The views and opinions expressed here are those of the authors, and no implication should be made to the Hong Kong SAR government. We thank Victor W. Gu for drawing Fig. 1.

\section{References}

Aanen DK, Kuyper TW, Hoekstra RF (2001) A widely distributed ITS polymorphism within a biological species of the ectomycorrhizal fungus Hebeloma velutipes. Mycol Res 105:284-290

Ainsworth GC, Kirk PM (2008) Ainsworth \& Bisby's dictionary of the fungi, 10th edn. CABI, Wallingford

Aveskamp MM, de Gruyter J, Woudenberg JHC, Verkley GJM, Crous PW (2010) Highlights of the Didymellaceae: a polyphasic approach to characterise Phoma and related pleosporalean genera. Stud Mycol 65:1-60

Berendsen RL, Pieterse CM, Bakker PA (2012) The rhizosphere microbiome and plant health. Trends Plant Sci 17(8):478-486

Bucher VVC, Hyde KD, Pointing SB, Reddy CA (2004) Production of wood decay enzymes, mass loss and lignin solubilization in wood by marine ascomycetes and their anamorphs. Fungal Divers 15:1-14

Burke DJ, Weintraub MN, Hewins CR, Kalisz S (2011) Relationship between soil enzyme activities, nutrient cycling and soil fungal communities in a northern hardwood forest. Soil Biol Biochem 43(4):795-803

Cai L, Jeewon R, Hyde KD (2005) Phylogenetic evaluation and taxonomic revision of Schizothecium based on ribosomal DNA and protein coding genes. Fungal Divers 19:1-21

Cai L, Jeewon R, Hyde KD (2006) Phylogenetic investigations of Sordariaceae based on multiple gene sequences and morphology. Mycol Res 110:137-150

Chang T-T (1995) A selective medium for Phellinus noxius. Eur J For Pathol 25(4):185-190

Deacon LJ, Pryce-Miller EJ, Frankland JC, Bainbridge BW, Moore PD, Robinson CH (2006) Diversity and function of decomposer fungi from a grassland soil. Soil Biol Biochem 38(1):7-20

Deng JX, Paul NC, Sang HK, Lee JH, Hwang YS, Yu SH (2012) First Report on Isolation of Penicillium adametzioides and Purpureocillium lilacinum from Decayed Fruit of Cheongsoo Grapes in Korea. Mycobiology 40(1):66-70

Felsenstein J (1985) Confidence-limits on phylogenies-an approach using the bootstrap. Evolution 39(4):783-791

Fujii K, Sugimura T, Nakatake K (2010) Ascomycetes with cellulolytic, amylolytic, pectinolytic, and mannanolytic activities inhabiting dead beech (Fagus crenata) trees. Folia Microbiol 55(1):29-34

Fukasawa Y, Osono T, Takeda H (2011) Wood decomposing abilities of diverse lignicolous fungi on nondecayed and decayed beech wood. Mycologia 103(3):474-482

Gams W (2007) Biodiversity of soil-inhabiting fungi. Biodivers Conserv 16(1):69-72

Gardes M, Bruns TD (1993) Its primers with enhanced specificity for basidiomycetes-application to the identification of mycorrhizae and rusts. Mol Ecol 2(2):113-118

Gazis R, Chaverri P (2010) Diversity of fungal endophytes in leaves and stems of wild rubber trees (Hevea brasiliensis) in Peru. Fungal Ecol 3(3):240-254

Grafenhan T, Schroers HJ, Nirenberg HI, Seifert KA (2011) An overview of the taxonomy, phylogeny, and typification of nectriaceous fungi in Cosmospora, Acremonium, Fusarium, Stilbella, and Volutella. Stud Mycol 68:79-113
Granchi L, Bosco M, Messini A, Vincenzini M (1999) Rapid detection and quantification of yeast species during spontaneous wine fermentation by PCR-RFLP analysis of the rDNA ITS region. J Appl Microbiol 87(6):949-956

Hall TA (1999) BioEdit: a user-friendly biological sequence alignment editor and analysis program for Windows 95/98/NT. Nucleic Acids Symp Ser 41:95-98

Huelsenbeck JP, Ronquist F (2001) MRBAYES: Bayesian inference of phylogenetic trees. Bioinformatics 17(8):754-755

Kodsueb R, McKenzie EHC, Lumyong S, Hyde KD (2008) Diversity of saprobic fungi on Magnoliaceae. Fungal Divers 30:37-53

Lacap DC, Hyde KD, Liew ECY (2003) An evaluation of the fungal 'morphotype' concept based on ribosomal DNA sequences. Fungal Divers 12:53-66

Lodge DJ (1997) Factors related to diversity of decomposer fungi in tropical forests. Biodivers Conserv 6(5):681-688

Lu BS (2000) Checklist of Hong Kong fungi. Fungal Divers Press, Hong Kong

Luangsa-Ard J, Houbraken J, van Doorn T, Hong SB, Borman AM, Hywel-Jones NL, Samson RA (2011) Purpureocillium, a new genus for the medically important Paecilomyces lilacinus. FEMS Microbiol Lett 321(2):141-149

Myllys L, Lohtander K, Tehler A (2001) Beta-tubulin, ITS and group I intron sequences challenge the species pair concept in Physcia aipolia and P. caesia. Mycologia 93(2):335-343

Newbound M, Mccarthy MA, Lebel T (2010) Fungi and the urban environment: a review. Landsc Urban Plan 96(3):138-145

Nylander JAA (2004) MrModeltest v2. Program distributed by the author. http://www.ebc.uu.se/systzoo/staff/nylander.html. Uppsala University: Evolutionary Biology Centre

O'Donnell K, Cigelnik E (1997) Two divergent intragenomic rDNA ITS2 types within a monophyletic lineage of the fungus Fusarium are nonorthologous. Mol Phylogenet Evol 7(1):103-116

Osono T, Takeda H (1999) Decomposing ability of interior and surface fungal colonizers of beech leaves with reference to lignin decomposition. Eur J Soil Biol 35(2):51-56

Page RDM (1996) TreeView: an application to display phylogenetic trees on personal computers. Comput Appl Biosci 12(4):357-358

Perez-de-Mora A, Burgos P, Madejon E, Cabrera F, Jaeckel P, Schloter M (2006) Microbial community structure and function in a soil contaminated by heavy metals: effects of plant growth and different amendments. Soil Biol Biochem 38(2):327-341

Rokas A, Carroll SB (2005) More genes or more taxa? The relative contribution of gene number and taxon number to phylogenetic accuracy. Mol Biol Evol 22(5):1337-1344

Samson RA, Houbraken J, Varga J, Frisvad JC (2009) Polyphasic taxonomy of the heat resistant ascomycete genus Byssochlamys and its Paecilomyces anamorphs. Persoonia 22:14-27

Samson RA, Yilmaz N, Houbraken J, Spierenburg H, Seifert KA, Peterson SW et al (2011) Phylogeny and nomenclature of the genus Talaromyces and taxa accommodated in Penicillium subgenus Biverticillium. Stud Mycol 70:159-183

Schoch CL, Seifert KA, Huhndorf S, Robert V, Spouge JL, Levesque CA et al (2012) Nuclear ribosomal internal transcribed spacer (ITS) region as a universal DNA barcode marker for Fungi. PNAS 109(16):6241-6246

Schwarze FWMR, Jauss F, Spencer C, Hallam C, Schubert M (2012) Evaluation of an antagonistic Trichoderma strain for reducing the rate of wood decomposition by the white rot fungus Phellinus noxius. Biol Control 61(2):160-168

Swofford DL (2002) PAUP*: phylogenetic analysis using parsimony (*and other methods). Version 4.0b10. Sinauer Associates, Sunderland

Thompson JD, Gibson TJ, Plewniak F, Jeanmougin F, Higgins DG (1997) The CLUSTAL_X windows interface: flexible strategies 
for multiple sequence alignment aided by quality analysis tools. Nucleic Acids Res 25(24):4876-4882

Viaud M, Pasquier A, Brygoo Y (2000) Diversity of soil fungi studied by PCR-RFLP of ITS. Mycol Res 104:1027-1032

White TJ, Bruns TL, Lee S, Taylor JW (1990) Amplification and direct sequencing of fungal ribosomal RNA genes for phylogenetics. PCR protocols: a guide to methods and applications. Academic Press, San Diego
Xu J, Ebada SS, Proksch P (2010) Pestalotiopsis a highly creative genus: chemistry and bioactivity of secondary metabolites. Fungal Divers 44(1):15-31

Yanna, Ho WH, Hyde KD (2002) Fungal succession on fronds of Phoenix hanceana in Hong Kong. Fungal Divers 10:185-211

Zhou DQ, Hyde KD (2001) Host-specificity, host-exclusivity, and host-recurrence in saprobic fungi. Mycol Res 105:1449-1457 